\title{
La disposición de los conflictos en el tiempo de la recepción en dos comedias de Calderón*
}

\author{
The arrangement of the conflicts in the time \\ of reception in two plays by Calderón
}

\author{
Miguel Martín Echarri \\ Universidad de Burgos \\ mrtnchrr@gmail.com \\ ORCID iD: http://orcid.org/0000-0001-8654-1366
}

RESUMEN: Toda obra de arte cuya recepción tenga lugar en el tiempo (la música, la literatura, el cine, etc.) experimenta la exigencia de ordenar de algún modo ciertos elementos en él: es posible analizar esa disposición (y no necesariamente atendiendo a su relación con el otro tiempo, virtual, de la ficción). Entre los géneros literarios, el teatro impone a las obras una limitada extensión y claridad en la expresión de las pretensiones, lo que facilita su detección. Proponemos ejemplificar con dos comedias de Calderón una propuesta metodológica para describir la distribución de conflictos en el tiempo escénico.

Palabras clave: tiempo de la recepción, Calderón, motivaciones, representación gráfica.

ABSTRACT: As every work of art that takes place over some time (such as music, literature, cinema, etc.) needs to have its elements temporally organised, it must be possible to describe this disposition (not necessarily in relation with the virtual, fictional time). Of the literary genres, theatre imposes reduced dimensions to each play, as well as clarity in the expression of the characters' aims, which makes them easier to detect. We propose to use two of Calderón's comedies as examples for the application of a method to describe the disposition of conflicts in the performance time.

Keywords: reception time, Calderón, motivations, graphic representation.

\footnotetext{
* La realización de los gráficos en este artículo se debe a la ayuda desinteresada de Alicia Sainz Esteban y Manuel Salviejo Delgado. La revisión del artículo debe mucho también a Alan Hynds y a Aurora Sainz Esteban.
} 


\section{INTRODUCCIÓN}

Toda obra de arte cuya recepción se estructura en el tiempo presenta necesariamente una determinada disposición cronológica de sus materiales. Un autor que no dé importancia a la previsión de los ritmos con que aparecen las unidades significantes no deja por eso de imponer un tempo al receptor, aunque sea descuidadamente.

Este factor ha sido reconocido y estudiado en relación con las obras musicales, quizás debido a la ausencia de un plano del contenido que desvíe la atención de los aspectos formales y su distribución en el devenir de la obra. Pero es común a todo discurso (no solo artístico) que se desarrolle en el tiempo. El cine y el teatro imponen a sus espectadores un tiempo tan exacto como el de la obra musical; también la lectura se produce en el tiempo aunque de una manera algo más flexible, pues permite al lector pausas, retrocesos y saltos ajenos a las intenciones del autor. Todas estas artes deben tener en cuenta un tiempo de la recepción ideal y disponer en él los elementos de su materia prima con coherencia y eficacia para lograr su comunicación y evitar el tedio.

Consiguientemente, el análisis de cualquier obra literaria deberá considerar ese parámetro y tratar de describir los ritmos que dibujan en el tiempo de la recepción los fenómenos percibidos por el lector-espectador. Cuáles sean esos fenómenos que se distribuyen en el tiempo de la recepción es una cuestión que depende seguramente de las convenciones de cada género.

No se trata aquí de analizar la relación entre ese tiempo de la recepción (representación, lectura, escucha, etc.) y el otro tiempo de la ficción (la historia, la acción representada, la fábula). Ese ha sido objeto de interés para muchos teóricos de la narración (Courtés, 1997: 103; Genette, 1989: 144-151) y del teatro (Ubersfeld, 1989: 144). En el estudio concreto del tiempo en la obra calderoniana, Déodat-Kessedjian (2002: 385) aparta explícitamente el plano de la representación de sus objetos de interés. Pero ninguno de ellos pretende mesurar el tiempo objetivo de la recepción ni describir la disposición de las acciones en él.

Es cierto que desde el punto de vista de la teoría hay poco que decir sobre la aparente homogeneidad del tiempo de la recepción; pero, aparte del interés de describir la disposición de los elementos que jalonan ese tiempo, otras fases de estudio ulteriores tendrán la posibilidad de llevar a cabo análisis críticos y comparativos que tengan en cuenta la eficacia diversa de los patrones, la tradición en que se insertan o que transgreden, etc. Ritmos variados pueden constituir formas capaces de adoptar significados complejos: una oposición paralela a la que encontramos entre sonata y rondó como "formas musicales" podría acaso ser estudiada entre la comedia de enredo y la tragedia. 


\section{PROPUESTA DESCRIPTIVA: LOS ELEMENTOS Y SU DISPOSICIÓN EN EL TIEMPO}

A diferencia de la narración (donde el tiempo de la historia puede detenerse en descripciones, etc.), el transcurrir del tiempo de la representación teatral implica siempre un transcurrir en el tiempo de la ficción, aunque sea con diferentes tempos y ordenaciones, así que el cambio no sirve para distinguir acontecimientos clave en el devenir del espectáculo en la misma medida que las acciones narradas pueden serlo en el relato. Pero la detección por parte del receptor de diferentes pretensiones en los personajes, cuya oposición desemboca en los conflictos, sí puede marcar un ritmo. Dejando de lado principios psicoanalíticos (Ubersfeld, 1989: 59), proponemos atender estrictamente a la expresión de la voluntad de los personajes, sus decisiones de hacer o lograr algo. No nos interesa ese "deseo" unitario que guía las acciones del personaje a lo largo de toda la obra, "bien deseado", o "valor orientador" (Couderc, 2006: 246, 259...), sino las opciones particulares que uno o varios personajes pueden adoptar en un momento dado y desechar poco después para luego retomarlas o asumir las de otro personaje.

DANTEO: Pues ¿qué has de hacer?

LIDORO: Encubrir

mi nombre hasta que, escribiendo

a mi padre, su asistencia

me adorne de lucimientos

dignos de decir quién soy, [...] (Calderón, 2013b: 163).

Aunque en última instancia cada receptor particular puede identificar o ignorar una motivación, debemos confiar en el propio tejido verbal de la obra literaria para encontrar en él su expresión o alusión. Será posible argumentar (y en su caso discutir) que la voluntad de hacer algo se expresa en un determinado pasaje, y, consiguientemente, describir la disposición temporal del entramado de pretensiones expresadas.

Los repertorios de pretensiones de los personajes pueden dibujar complejos esquemas de tensiones, y podremos superponer y comparar los que extraigamos de obras diferentes para sacar conclusiones más generales sobre las maneras de diseñar esta disposición temporal de los acontecimientos escénicos o narrativos, así como discutir la eficacia dispar de unos y otros modelos.

Para describir el plano temporal de la obra literaria, podemos imitar a los analistas musicales cuando recurren a las letras del alfabeto para ir nombrando los distintos temas reconocibles en una obra por el mismo orden en que aparecen. Aunque hay otros métodos para analizar las formas musicales (como los de Schenker y sus continuadores, o Kühn, entre otros), el principio básico está bien explicado por Cook (2004: 164): identificamos con la letra A al primer elemento temático reconocible que aparece; identificamos con la $\mathrm{B}$ al segundo, 
con la $\mathrm{C}$ al tercero, etc. Por su parte, las posteriores variaciones de A serán A', A" etc.; las variaciones o desarrollos de B serán B', B", etc.

El método nos interesa para aplicarlo a las motivaciones de los personajes en el mismo orden en que se declaran o sugieren a lo largo de la representación, y que son las que generan los conflictos cuando entran en colisión de manera alusiva o explícita. En otros casos la tensión puede pasar desapercibida al personaje pero resultar obvia para el público por medio de diversos recursos teatrales.

De manera coherente con esta posibilidad, en cada obra se hace necesario describir el repertorio de elementos que forman el esquema: ponerle nombre a la motivación que corresponde a la letra $\mathrm{A}$, a la A', a la $\mathrm{B}$, etc., y a los personajes o grupos de personajes que las ostentan. Cada vez que se repita su expresión a lo largo de la obra, habrá que señalar su posición, tanto si choca con otra voluntad como si es compatible con ella. También puede ocurrir que una motivación sea compartida por varios personajes simultánea o sucesivamente, como cuando un enfrentamiento da lugar a un acuerdo por una causa común. Se trata de generar un esquema del conjunto de motivaciones que aparecen en cada obra (asociadas a uno o más personajes), de modo que el esquema general del tiempo de la recepción de la obra aparezca objetivamente indicado.

\section{UN EJEMPLO: DOS COMEDIAS DE CALDERÓN}

Entre los posibles textos a los que podríamos aplicar el método descriptivo que acabamos de proponer, hemos optado por limitarnos a comparar dos ejemplos sumamente homogéneos. Trataremos de explicar las razones más concretas por las que hemos elegido dos comedias calderonianas.

En primer lugar, el peculiar tiempo semirrígido del texto teatral en su representación obliga a una conciencia de su desarrollo cronológico mucho mayor de la que permite la enorme libertad de la narrativa, cuyo tiempo de recepción es totalmente flexible (admite del lector todo tipo de interrupciones, saltos, repasos, etc.); curiosamente, también es una exigencia mayor de lo que es habitual en el caso del guion cinematográfico, donde la palabra sugiere el paso del tiempo de una forma también más libre, en la medida en que será el montaje el encargado de dar al tiempo su configuración definitiva. Ni tan flexible como la novela ni tan rígido como una proyección cinematográfica, el teatro tiene un tiempo que se repite más o menos de representación en representación, condición que exige una planificación mayor por parte del dramaturgo.

Efectivamente, la estructura temporal de la lectura no puede ser estudiada según un tiempo de lectura externo, sino según el tiempo especulativo de un lector modelo que se tomase solo pequeños descansos entre capítulo y capítu- 
lo, pero sin abandonar la lectura continuada de Guerra y paz hasta haber terminado. En el teatro, en cambio, el desarrollo material y externo de una actuación particular es el que realmente llega al receptor real. A diferencia del lector de cualquier tipo de ficción literaria (novela, poema, teatro leído), el espectador teatral no participa en la configuración del tiempo, debida solo a los responsables del espectáculo, más o menos fieles al autor. Si la lectura privada admite idas y vueltas, cambios de velocidad, descansos, despistes, etc., la representación del texto es en principio imparable.

Ubersfeld (1989: 181) compara el texto teatral con una partitura en el sentido de que es también un conjunto de órdenes para la compañía que va a interpretar la obra. Efectivamente, como el tiempo de la música, el tiempo de la representación viene condicionado y codificado por escrito y se realiza en una performance concreta, única, efímera. Es muy distinto por tanto del tiempo del habla: en la representación (salvo en casos de improvisación) no hay libertad para establecer cualquier disposición temporal de los signos, sino que se sigue un programa establecido previamente.

Por su parte, el tiempo del cine está fosilizado por el montaje, si bien la recepción doméstica común en nuestros tiempos incrementa el poder del receptor (y esto indudablemente ha influido en su código, que ya no puede aprovecharse de la paciencia del público cautivo de las salas, como hacía el cine clásico). Pero el tiempo del teatro nunca se repite con exactitud, de ahí que el guion no dé una pauta del tiempo del film en el mismo grado que el texto teatral (especialmente en la tradición de la comedia aurisecular).

Otra razón por la que un estudio del tempo puede ser más provechoso en relación con las formas teatrales es que están obligadas a limitarse de una manera bastante estricta a un plazo temporal que viene condicionado por la capacidad de atención del auditorio. A partir de esa exigencia de brevedad, en su desarrollo en el doble tiempo de la representación y la ficción, los géneros teatrales están muy apegados a modelos repetibles, a convenciones que imponen también sus normas en este ámbito. Es palpable la diferencia en relación con la relativa libertad formal de la novela o el poema, cuya dimensión es mucho más diversa. La comedia barroca se divide casi siempre en tres actos de una longitud poco variable y comparte siempre la intención de entretener al público (lo cual no es necesariamente común a muchos otros géneros literarios). Las limitaciones de atención del público fuerzan al autor a ser conciso y darse prisa en presentar motivaciones claras.

En este sentido, pocas tradiciones dramáticas son tan pragmáticas como la barroca hispánica en lo que respecta a la duración del espectáculo y a la perfecta adecuación al texto escrito. La homogeneidad en la duración de las obras seguramente permita una comparación relativamente estricta para llegar a modelos concretos de disposición de los conflictos. Si no se da una perfecta 
transparencia entre ellas, al menos podrán describirse algunos rasgos comunes a las obras analizadas y descritas, de manera que nos acerquemos al probable código que distribuye los elementos en el eje del tiempo de la representación.

De momento debemos conformarnos con aplicar el modelo descriptivo a una pareja mínima de obras comparables: se trata de obtener descripciones similares de objetos similares antes de atrevernos a dar cuenta de la heterogeneidad de los múltiples géneros en las innumerables tradiciones teatrales. Por esas razones, parece sensato limitarse a dos comedias de un único autor.

Entre otras posibilidades, las comedias mitológicas son un género caracterizado por el interés formal y ornamental en su adaptación de argumentos extraídos de los mitos. Sin despreciar la posibilidad de aplicar el mismo método a cualquier otro género teatral áureo, elegimos El mayor encanto, amor (Calderón, 2013a), comedia de 1635 editada en 1637, pero revisada en un manuscrito posterior de 1668, y La dama y galán Aquiles (Calderón, 2013b) que fue representada en 1667 y se conserva en un manuscrito corregido por el autor. Ambas tienen una historia textual relativamente clara: optamos siempre por las lecturas propuestas en las ediciones citadas.

Primero nos interesará comprobar si la representación gráfica que proponemos traduce de forma plausible la información que se encuentra en una comedia cualquiera, reduciéndola al aspecto que nos hemos propuesto considerar. Después será interesante tratar de compararlas entre sí o superponerlas para medir el grado de parecido que encontramos entre ellas. Tal vez empezará a ser posible generar una tipología con nombres para los distintos esquemas-formas que se repitan en las variadas comedias que podamos describir en el futuro (como las formas musicales de "sonata", "rondó", "fuga"...).

\section{Particularidades Del teAtro ÁUReo}

Como todo sistema de convenciones, el teatro aurisecular presenta algunas particularidades que no podemos dejar de considerar antes de aplicarle un método generalizador.

En primer lugar, los elementos que el autor utiliza en su disposición rítmica del texto están tomados de un repertorio particular: canciones y música, expansiones culteranas, intervenciones cómicas no siempre recogidas en las ediciones impresas, elementos parateatrales como juegos, competiciones de ingenio, etc. (Arellano, 2001: 19-57, entre otros), son recursos cuyo conocimiento orientaba al espectador, de modo que su complejo significado no puede limitarse a la duración en el tiempo.

Lo mismo ocurre con la estructuración de los conflictos en la trama, que no es una simple alternancia sino una cuidada jerarquía ordenada según nor- 
mas compartidas. Un código teatral - situado dentro del sistema de los códigos sociales - daba las coordenadas para reconocer la importancia relativa de cada conflicto. Las tramas constituyen diseños particulares, con frecuencia semejantes pero nunca exactamente iguales. A partir de la descripción de un corpus mucho mayor que el que proponemos podría desarrollarse una tipología de las motivaciones y conflictos presentes en el conjunto de las comedias, o incluso de las formas que adoptan las comedias según jerarquías de conflictos.

Tampoco su expresión es siempre idéntica, sino que los autores disponen de mecanismos intercambiables o redundantes para dar a entender una misma acción: el compromiso de un personaje con una decisión; su enfrentamiento físico o verbal con otros personajes presentes en escena; la narración posterior; la discusión e interpretación de lo ocurrido; la exposición de sentimientos derivados bajo forma lírica; por último, el recurso de conceder un tiempo sin novedades para permitir que el espectador ordene lo visto y oído.

Estas distinciones muestran que una descripción de los acontecimientos como la que proponemos es incompleta, puesto que no puede dar cuenta de la riqueza del código (y lo mismo ocurriría si hubiéramos elegido cualquier otro: la novela realista, el apólogo medieval, etc.). Sin embargo, aun reconociendo que el método puede matizarse si se sistematiza el orden de convenciones en que aparece cada texto, la dimensión del tiempo de la recepción merece nuestra atención y sin duda justifica el intento de describirlo.

\section{OTRAS PROPUESTAS}

Podría pensarse que merece la pena sustituir los conflictos y motivaciones por los "motivos", acciones que somos capaces de identificar porque se repiten de obra en obra. Oleza (2009: 323) ha propuesto explicitar un repertorio de los que se repiten en las comedias. Pero, si se identifican al reaparecer en obras distintas, estas unidades se escaparán al análisis de una obra aislada. Ciertamente, no todos los acontecimientos que pueden llegar a aparecer en una comedia estarán representados en una lista de elementos recurrentes. La configuración del ritmo de una obra dramática no depende de que las acciones sean compartidas con otras obras, sino de que sean perceptibles en su interior.

Algunas propuestas formalizan los principios estructurales de la comedia aurisecular: Weber de Kurlat (1975 y 1976) aplica a la obra de Lope los principios de Propp y Greimas, y Serralta (1987) busca en la de Solís una mecánica del enredo (basada en las dos parejas de amantes y sus entrecruzamientos conflictivos) que se repite con adaptaciones en cada obra. Mientras Arellano (2006: 173) propone aplicar a Calderón estas posibilidades, Couderc (2006) escoge un corpus de comedias de la generación de Lope para un análisis "funcionalista". 
Pero se trata de aplicaciones de los estudios narratológicos a la estructura semántica de la comedia, no al diseño del tiempo escénico.

La jerarquía entre personajes, con sus deseos y motivaciones, corresponde a un análisis de la estructura semántica global de la obra, que solo puede ser comprendida a partir de su desenlace (Couderc, 2006: 247, 289) o, al menos, de recapitulaciones provisionales. Para entender el discurrir de los conflictos y la dinámica de su comprensión, por el contrario, debemos dejar de lado su resultado. En La dama y galán Aquiles, por ejemplo, Lidoro puede parecer al principio el galán protagonista (A), pero pronto se desplaza a la posición de competidor (C), para finalmente resultar el galán suelto. Si la comprensión de esa estructura solo se aclara al final, es obvio que no podemos tenerla en cuenta para entender la dosificación del entretenimiento.

El mismo problema encontramos con la posibilidad de señalar las distintas fases en el desarrollo de un conflicto: planteamiento, enfrentamientos sucesivos, complicaciones, resolución. Se trata de una comprensión de los cambios que solo es posible desde la óptica de la obra finalizada. Muchas veces una aparente conclusión no es sino la base para una inesperada complicación, juego de metamorfosis que es uno de los objetivos principales del asombro barroco. El tiempo de la recepción real carece del aparato crítico imprescindible para semejante comprensión global, y es esa perplejidad del espectador la que debemos apreciar en su justa medida.

Por último, nos encontramos con el problema ampliamente discutido pero siempre polémico de la segmentación del teatro en unidades mínimas, que desde el punto de vista teórico ha sido tratado por Ubersfeld (1989: 167) y FischerLichte (1999: 261-266, 596-607). En lo que corresponde específicamente a Calderón, Antonucci (2010) recoge el estado de una cuestión muy debatida entre partidarios y detractores de una segmentación basada en la versificación, que aparece como problemática pero insustituible.

Aunque aquí no pretendemos solucionar estas dificultades filológicas, debemos reconocer que tanto los cambios métricos como los vacíos escénicos o los cambios de circunstancia espacio-temporal (rasgos que han servido como criterios de segmentación) tienen una incuestionable influencia en el ritmo, y se complementan con el diseño de los conflictos que proponemos estudiar.

\section{APLICACIÓN DEL MÉTODO}

En el caso de la comedia áurea, contamos con una relativa uniformidad del transcurso del tiempo escénico medido en versos que, sin tener la misma cantidad silábica, presentan una oscilación mínima (entre 7 y 11 sílabas, normalmente, predominando los de 8), especialmente si se compara con las di- 
mensiones que presentan los segmentos que en cada obra se destinan a explicar las distintas motivaciones de los personajes. La alternativa de computar palabras o sílabas es incuestionablemente más farragosa. Consecuentemente, mediremos la duración en versos para entender las variaciones de extensión de cada motivación o de los entretenimientos vacíos, así como a su posible simultaneidad, alternancia más o menos ágil, etc.

En una tabla sistemática y diferenciada para cada comedia, explicitaremos las motivaciones que se declaran (o sugieren) a lo largo del texto, marcando los números de los versos que se ocupan para mostrar esas motivaciones de los personajes. Es obvio que realizaremos la transcripción de las motivaciones siguiendo unos criterios particulares que podremos defender pero que podrían haber sido otros. A diferencia de otros códigos teatrales (el drama realista, la tragedia isabelina, el teatro del absurdo, etc.) estos textos son bastante claros: en todo momento son evidentes las pretensiones de los personajes, así que confiamos en que nuestra lectura sea al menos una de las varias posibles y que no violente la interpretación con sus pretensiones objetivadoras, consintiendo que los esquemas y gráficos informen realmente de la disposición de las comedias descritas.

Las tablas 1 y 2 presentan una primera columna que recoge el número del verso en el que empieza a explicitarse una pretensión por parte de algún personaje; una segunda columna recoge un breve resumen argumental para entender esa motivación (los personajes calderonianos suelen declarar en todo momento sus intenciones y deseos, lo que hace que el resumen de la obra coincida prácticamente con el esquema de las intenciones de los personajes); una tercera columna muestra la formalización de lo resumido por medio del nombre del personaje que experimenta la inclinación y la letra que le corresponde por su orden de aparición. Cuando una motivación A deriva en otra A', la sucederá inmediatamente antes de pasar a otra motivación $\mathrm{B}$ con sus derivadas. Cuando dos o más intenciones aparecen simultáneamente se recogen separadas por una coma; cuando resultan conflictivas entre sí se enfrentan por medio de un guion.

En los esquemas 1 y 2 ofrecemos el repertorio de pretensiones que ocurren en cada obra, con los personajes que les sirven de sujeto. 


\begin{tabular}{|c|c|c|}
\hline \multicolumn{3}{|c|}{ El mayor encanto, amor } \\
\hline Verso & Resumen de acciones e intenciones & Motivaciones \\
\hline \multicolumn{3}{|c|}{ PRIMERA JORNADA } \\
\hline 1 & Ulises, Antistes, Arquelao, Lebrel... sufren una tempestad. & Griegos-A \\
\hline 23 & Se calma el mar y se ve tierra. Desembarcan. & \\
\hline 51 & Ulises se pregunta por la geografía a la que han llegado. & Griegos-A' \\
\hline 96 & $\begin{array}{l}\text { Al ir a cortar Ulises un árbol, se quejan Lísidas y Flérida } \\
\text { (identidades de los árboles). }\end{array}$ & Lísidas y Flérida B \\
\hline 121 & $\begin{array}{l}\text { Vienen fieras al encuentro de Ulises y Clarín, que quieren } \\
\text { defenderse del peligro. }\end{array}$ & Ulises y Clarín-A”, \\
\hline 130 & Las fieras rendidas hacen señas para que huyan. & $\begin{array}{l}\text { Ulises, Clarín, } \\
\text { fieras-A',', } \\
\text { algo ignoto }\end{array}$ \\
\hline 164 & $\begin{array}{l}\text { Antistes vuelve alarmado y cuenta que Circe ha ofrecido un } \\
\text { bebedizo a los hombres de Ulises, que se han convertido en } \\
\text { animales. Antistes ha escapado porque tardó un poco en } \\
\text { beber y pasó desapercibido a Circe. Propone huir. }\end{array}$ & $\begin{array}{l}\text { Griegos A","'- } \\
\text { Circe C }\end{array}$ \\
\hline 295 & Ulises quiere salvar a los compañeros. & Ulises D-Circe C \\
\hline 299 & $\begin{array}{l}\text { Ulises pide ayuda a Juno contra Venus. Personajes } \\
\text { celestiales despliegan un arco iris en señal de apoyo y } \\
\text { otorgan un ramillete mágico a Ulises. }\end{array}$ & $\begin{array}{l}\text { Juno e Iris, Ulises } \\
\text { D-Circe y Venus C }\end{array}$ \\
\hline 377 & Llega Circe, que finge una bienvenida y le ofrece de beber. & Circe C-Ulises A",', \\
\hline 453 & $\begin{array}{l}\text { Antes de beber, Ulises moja el ramillete en la poción, sale } \\
\text { fuego del vaso. Parece que Circe acepta su derrota. Salen } \\
\text { los marineros como personas. }\end{array}$ & $\begin{array}{l}\text { Parecen finalizar } \\
\text { C y D }\end{array}$ \\
\hline 502 & $\begin{array}{l}\text { Ulises quiere volver al barco y marcharse. Circe quiere } \\
\text { retenerlo. }\end{array}$ & $\begin{array}{l}\text { Ulises A' y A','’- } \\
\text { Circe E }\end{array}$ \\
\hline 511 & $\begin{array}{l}\text { Ulises cuenta toda su historia. Hasta aquí el público quería } \\
\text { saber quiénes eran estos náufragos (satisfacción de una } \\
\text { tensión implícita en A). }\end{array}$ & \\
\hline 585 & $\begin{array}{l}\text { Ulises reitera su deseo de marcharse. Circe reitera su } \\
\text { acogida y cuenta su historia (en reciprocidad con el } \\
\text { discurso de Ulises). Se satisface el deseo del público de } \\
\text { saber quién es Circe. Pondera su poder, pero no da razón } \\
\text { concreta de su deseo de dominar. Vuelve a pedirle que se } \\
\text { quede (le ha gustado). }\end{array}$ & $\begin{array}{l}\text { Ulises A' y A','”- } \\
\text { Circe E }\end{array}$ \\
\hline 801 & $\begin{array}{l}\text { En un aparte, Ulises dice querer librar a todos los } \\
\text { prisioneros de Circe. }\end{array}$ & Ulises F-Circe C \\
\hline 807 & $\begin{array}{l}\text { Antistes recuerda aparte a Ulises las trampas de Circe y } \\
\text { pide que se marchen. }\end{array}$ & $\begin{array}{l}\text { Antistes A,",'- } \\
\text { Circe E (y } \\
\text { probablemente C) }\end{array}$ \\
\hline 817 & $\begin{array}{l}\text { Circe ofrece un favor a Ulises, que pide la libertad de los } \\
\text { dos árboles del principio. Circe cuenta su delito antes de } \\
\text { darles la libertad. }\end{array}$ & \\
\hline 853 & $\begin{array}{l}\text { Lísidas y Flérida dicen sendos sonetos. Reconocen su } \\
\text { deuda con Ulises. }\end{array}$ & $\begin{array}{l}\text { (Acaba B). Lísidas } \\
\text { y Flérida G }\end{array}$ \\
\hline 891 & Circe celebra con música la permanencia de Ulises. & \\
\hline
\end{tabular}




\begin{tabular}{|c|c|c|}
\hline 902 & $\begin{array}{l}\text { Entra Arsidas. Declara su amor a Circe y su rivalidad con } \\
\text { Ulises. Circe le ha perdonado cruelmente porque cree que } \\
\text { en forma humana sufre más por su amor. }\end{array}$ & Arsidas H-Circe E \\
\hline 962 & $\begin{array}{l}\text { Todos concluyen en apartes: Ulises fingirá amor para } \\
\text { destruir a Circe, y ella para destruir a Ulises. }\end{array}$ & $\begin{array}{l}\text { Ulises F, } \\
\text { Circe C o E, } \\
\text { Arsidas H, }\end{array}$ \\
\hline \multicolumn{3}{|c|}{ SEGUNDA JORNADA } \\
\hline 996 & $\begin{array}{l}\text { Libia desea que la tristeza de Circe se deba al amor para } \\
\text { que otorgue libertad a sus damas. Astrea le da la razón. }\end{array}$ & $\begin{array}{l}\text { Libia y Astrea I- } \\
\text { Circe C' }\end{array}$ \\
\hline 1030 & $\begin{array}{l}\text { Circe se queda sola con Flérida, que teme ser castigada de } \\
\text { nuevo. Quiere a Lísidas, pero teme a Circe. }\end{array}$ & Flérida B-Circe C' \\
\hline 1037 & $\begin{array}{l}\text { Circe se confiesa con Flérida: está enamorada de Ulises en } \\
\text { conflicto con sus votos anteriores. }\end{array}$ & Circe E'-Circe C' \\
\hline 1094 & $\begin{array}{l}\text { Circe le ordena a Flérida que enamore a Ulises por el día } \\
\text { para sustituirla en la cama. Flérida rechaza la idea porque } \\
\text { ama a Lísidas: no puede disimular su amor a este y simular } \\
\text { su amor a aquel. Circe lo exige precisamente porque solo } \\
\text { ella no le dará celos, al estar ya enamorada de otro. }\end{array}$ & $\begin{array}{l}\text { Circe E"' y C' - } \\
\text { Flérida B }\end{array}$ \\
\hline 1137 & $\begin{array}{l}\text { Llegan dos griegos, y ellas se esconden a escuchar: Lebrel } \\
\text { está feliz aquí, Clarín quiere volver a Grecia, e insulta a } \\
\text { Circe. }\end{array}$ & Clarín J-Circe C'” \\
\hline 1193 & $\begin{array}{l}\text { Surge Circe y Clarín finge que era Lebrel quien hablaba } \\
\text { mal. }\end{array}$ & $\begin{array}{l}\text { Circe C',-Clarín } \\
\text { A',,, / Clarín A,,,', } \\
\text { Lebrel A",,, }\end{array}$ \\
\hline 1211 & $\begin{array}{l}\text { Circe expulsa a Lebrel y premia a Clarín (el premio tendrá } \\
\text { engaño y será un castigo). }\end{array}$ & $\begin{array}{l}\text { Lebrel y Clarín K- } \\
\text { Circe C," }\end{array}$ \\
\hline 1228 & Llega Ulises. Circe recuerda que empieza el juego. & Circe E"' \\
\hline 1234 & $\begin{array}{l}\text { Ulises confiesa en aparte que está enamorado de Circe, } \\
\text { pero evidentemente tiene miedo. }\end{array}$ & $\begin{array}{l}\text { Ulises L- } \\
\text { Ulises A,", }\end{array}$ \\
\hline 1244 & $\begin{array}{l}\text { Circe le invita a una fiesta esta noche. Ulises contesta con } \\
\text { un requiebro, pero ella le corta y él se excusa llamándolo } \\
\text { cortesía, lo cual ella lamenta. }\end{array}$ & $\begin{array}{l}\text { Ulises L-Circe C', / } \\
\text { Ulises A,",'- } \\
\text { Circe E' }\end{array}$ \\
\hline 1282 & $\begin{array}{l}\text { Se sientan, y Circe vuelve a exigirle a Flérida que lo } \\
\text { seduzca. }\end{array}$ & $\begin{array}{l}\text { Circe E'” y C'- } \\
\text { Flérida B }\end{array}$ \\
\hline 1293 & $\begin{array}{l}\text { Flérida se sienta junto a Ulises por obvio temor a Circe y } \\
\text { pese a su lealtad a Lísidas. }\end{array}$ & Flérida M y M'-B \\
\hline 1295 & Momento en que Lísidas llega y lo ve. & Lísidas B-[M'] \\
\hline 1300 & $\begin{array}{l}\text { Antistes en aparte señala el riesgo de que Ulises se } \\
\text { enamore como obstáculo para volver a Grecia. }\end{array}$ & Antistes A'-Ulises L \\
\hline 1304 & $\begin{array}{l}\text { La música da un respiro que permite reordenar } \\
\text { mentalmente la situación: tanto Ulises como Circe se } \\
\text { proponían enamorar al otro, pero ambos han caído es sus } \\
\text { respectivas trampas sin querer reconocerlo. }\end{array}$ & \\
\hline 1308 & $\begin{array}{l}\text { Arsidas llega celoso y se sienta al otro lado de Circe con la } \\
\text { idea de obstaculizar el coqueteo. }\end{array}$ & $\begin{array}{l}\text { Arsidas H- } \\
\text { Circe E' y E', }\end{array}$ \\
\hline 1329 & $\begin{array}{l}\text { Circe propone un juego de preguntas y respuestas para } \\
\text { pasar el rato. Flérida expondrá una historia (trasunto de la }\end{array}$ & Arsidas H-Ulises L \\
\hline
\end{tabular}




\begin{tabular}{|c|c|c|}
\hline & $\begin{array}{l}\text { suya) y los demás deberán interpretarla. Ulises y Arsidas } \\
\text { centran la discusión: Ulises defiende que es más difícil } \\
\text { disimular un amor verdadero, Arsidas que simular uno } \\
\text { falso. Llegan a las armas. }\end{array}$ & \\
\hline 1393 & $\begin{array}{l}\text { Circe se interpone. Impone a Ulises que finja (pues le } \\
\text { parece fácil) y a Arsidas que disimule (por lo mismo). } \\
\text { Arsidas acusa a Ulises de hacer trampa porque ya está } \\
\text { enamorado, pero acepta. }\end{array}$ & $\begin{array}{l}\text { Arsidas H-Ulises L- } \\
\text { Circe E' }\end{array}$ \\
\hline 1442 & $\begin{array}{l}\text { Circe se aleja, llama a Arsidas, que la rehuye, mientras } \\
\text { Ulises la sigue. }\end{array}$ & Ulises L' \\
\hline 1462 & $\begin{array}{l}\text { Flérida busca a solas a Ulises, le agradece su acción } \\
\text { bienhechora y logra de él un abrazo (honesto). }\end{array}$ & Flérida M' \\
\hline 1490 & $\begin{array}{l}\text { Lísidas por un lado y Circe por otro llegan y lo ven: él se } \\
\text { lamenta porque la deuda con Ulises le impide vengarse; } \\
\text { ella no sabe hasta qué punto finge Flérida y le gustaría que } \\
\text { no le importase. }\end{array}$ & $\begin{array}{l}\text { Lísidas G-B; } \\
\text { Circe E'-C'-M' }\end{array}$ \\
\hline 1502 & $\begin{array}{l}\text { Flérida cita a Ulises como había pactado con Circe, pero él } \\
\text { la rechaza porque debe fingir amor a Circe. }\end{array}$ & $\begin{array}{l}\text { Flérida M'-Ulises L' } \\
\text { (y L) }\end{array}$ \\
\hline 1522 & $\begin{array}{l}\text { Flérida se muestra contenta. Lísidas quiere hablar con ella } \\
\text { pero Circe se adelanta y él sigue escondido. Circe le dice } \\
\text { que acabe con sus fingimientos. (Su deseo de acostarse con } \\
\text { Ulises —que pasa por la estrategia de que Flérida lo } \\
\text { enamore - va contra su amor a Ulises: genera sus celos). }\end{array}$ & $\begin{array}{l}\text { Circe E'-E', } \\
\text { y Flérida M', }\end{array}$ \\
\hline 1552 & $\begin{array}{l}\text { Aparece Lísidas con sus quejas: no puede decidirse entre } \\
\text { creer lo que Flérida le ha dicho a Ulises o lo que le ha } \\
\text { dicho a Circe. Se va a los montes. }\end{array}$ & $\begin{array}{l}\text { Lísidas G- } \\
\text { Flérida M' }\end{array}$ \\
\hline 1592 & $\begin{array}{l}\text { Clarín está en el monte donde va a cobrar su regalo de } \\
\text { Circe. Llama a Brutamonte, que resulta ser un gigante, que } \\
\text { le explica su deseo de vengar a Polifemo en los griegos, } \\
\text { aunque se reprime por obediencia a Circe y le da una caja. } \\
\text { Diálogo cómico. }\end{array}$ & $\begin{array}{l}\text { Clarín K- } \\
\text { Brutamonte N }\end{array}$ \\
\hline 1660 & $\begin{array}{l}\text { Clarín abre la caja y sale una dueña que llama a un enano, } \\
\text { que le acompañarán en adelante y oirán todo lo que diga } \\
\text { (tortura cómica). }\end{array}$ & Clarín $\mathrm{O}$ \\
\hline 1731 & $\begin{array}{l}\text { Llega Lebrel huyendo de Circe. Clarín le entrega su regalo, } \\
\text { que cuando llega a manos de Lebrel se transforma en joyas. } \\
\text { Lebrel coge una parte para compartirlas con Libia. }\end{array}$ & Clarín O-Lebrel P \\
\hline 1787 & $\begin{array}{l}\text { Se queda solo Clarín y vuelven a salir la dueña y el enano. } \\
\text { Por azar pronuncia el nombre del gigante, que aparece } \\
\text { también. }\end{array}$ & Clarín O \\
\hline 1834 & $\begin{array}{l}\text { Llega Lebrel con Astrea y Libia. Astrea quiere que Clarín } \\
\text { comparta sus joyas con ella. No se cree las locuras de } \\
\text { Clarín. }\end{array}$ & Astrea Q-Clarín O \\
\hline 1862 & $\begin{array}{l}\text { Llega Circe (y han huido Libia y Astrea). Se encuentra con } \\
\text { Clarín y por una mala frase lo convierte en mona parlante. }\end{array}$ & $\begin{array}{l}\text { Circe C"'-Clarín O } \\
\text { y A",", }\end{array}$ \\
\hline 1892 & $\begin{array}{l}\text { Se queda sola Circe. Ulises llega. Siguen con sus } \\
\text { fingimientos. Ulises le cuenta la caza que acaba de } \\
\text { protagonizar: y se compara con la garza, dando muestras de }\end{array}$ & $\begin{array}{l}\text { Ulises L-L'; } \\
\text { Circe E'-C' }\end{array}$ \\
\hline
\end{tabular}




\begin{tabular}{|c|c|c|}
\hline & $\begin{array}{l}\text { su amor. Circe le dice que deje de fingir amor, pues están } \\
\text { solos. }\end{array}$ & \\
\hline 1995 & $\begin{array}{l}\text { Ulises confiesa ser verdadero su amor fingido. Circe dice } \\
\text { que no le castiga porque viene gente. }\end{array}$ & Ulises L-Circe C' \\
\hline 2014 & Arsidas vuelve a decir sus celos. & Arsidas H \\
\hline 2024 & $\begin{array}{l}\text { Circe los invita a todos a sentarse para cenar servidos por } \\
\text { una mesa mágica. }\end{array}$ & \\
\hline 2050 & $\begin{array}{l}\text { Cajas, y Libia explica que Brutamonte se ha rebelado para } \\
\text { destruir a los griegos con un ejército de cíclopes. }\end{array}$ & $\begin{array}{l}\text { Brutamonte N-Circe } \\
\text { y griegos A,,,, }\end{array}$ \\
\hline 2092 & Ulises y Arsidas, en paralelo, se ofrecen a pelear. & $\begin{array}{l}\text { Ulises y Arsidas D'- } \\
\text { Brutamonte N }\end{array}$ \\
\hline 2104 & $\begin{array}{l}\text { Circe los detiene: era una prueba para Ulises y Arsidas. } \\
\text { Ahora discuten sobre cuál de los dos hizo mejor, si Ulises } \\
\text { que fue rápido a las armas o Arsidas que primero acudió a } \\
\text { Circe. Pelean y los griegos se ponen con Ulises y las fieras } \\
\text { de Trinacria con Arsidas, su rey. }\end{array}$ & $\begin{array}{l}\text { Ulises L y L'- } \\
\text { Arsidas H }\end{array}$ \\
\hline 2194 & $\begin{array}{l}\text { Circe apaga la luz, desata una tormenta, y ellos riñen a } \\
\text { oscuras. }\end{array}$ & $\begin{array}{l}\text { Circe C'-Ulises L- } \\
\text { Arsidas H }\end{array}$ \\
\hline \multicolumn{3}{|c|}{ TERCERA JORNADA } \\
\hline 2226 & $\begin{array}{l}\text { Antistes recapitula incluyendo lo que ha pasado después: } \\
\text { Arsidas ha huido, tal vez para preparar la venganza, y } \\
\text { Ulises está entregado al placer con Circe. Propone fingir } \\
\text { una guerra para recuperar la voluntad de Ulises y } \\
\text { marcharse en el barco. }\end{array}$ & Antistes J \\
\hline 2321 & Lebrel aconseja no hacerlo, por miedo a Circe. & Lebrel R-Antistes J \\
\hline 2336 & $\begin{array}{l}\text { Lebrel se queda solo. Quiere cazar una mona para llevarla a } \\
\text { Grecia y enseñarla por negocio. Llega Clarín de mona } \\
\text { (habla, pero no para Lebrel) y Lebrel lo caza. }\end{array}$ & $\begin{array}{l}\text { Lebrel S-Clarín T } \\
\text { (no lo dice } \\
\text { claramente) }\end{array}$ \\
\hline 2394 & $\begin{array}{l}\text { Llegan Astrea y Libia. Recapitulan sobre lo ocurrido con } \\
\text { Clarín. }\end{array}$ & \\
\hline 2422 & $\begin{array}{l}\text { Circe y Ulises recapacitan sobre sus situaciones, } \\
\text { finalizando el conflicto debido a sus amores. Ulises se } \\
\text { duerme. }\end{array}$ & \\
\hline 2507 & $\begin{array}{l}\text { Llaman al arma. Ulises despierta y quiere ir a pelear. } \\
\text { Antistes explica que es salva de saludo, pero Ulises sigue } \\
\text { su impulso. Circe lo retiene con músicas. Antistes explica } \\
\text { la situación vergonzosa en que Ulises se encuentra. }\end{array}$ & $\begin{array}{l}\text { Antistes J-Ulises- } \\
\text { Circe E }\end{array}$ \\
\hline 2595 & Vence amor. & \\
\hline 2614 & $\begin{array}{l}\text { Arsidas convierte la ficción en realidad: viene con guerra y } \\
\text { ayudado por Lísidas, tal como explica Flérida. }\end{array}$ & $\begin{array}{l}\text { Arsidas H y Lísidas } \\
\text { B-Ulises L y Circe E }\end{array}$ \\
\hline 2722 & $\begin{array}{l}\text { Circe convoca a sus ejércitos de damas y encantos contra } \\
\text { ellos. No quiere despertar a Ulises. }\end{array}$ & $\begin{array}{l}\text { Circe C' y E-Arsidas } \\
\text { H y Lísidas B }\end{array}$ \\
\hline 2774 & $\begin{array}{l}\text { Arsidas quiere acabar con Circe y sus encantos. Lísidas } \\
\text { quiere liberar a Flérida de Circe. }\end{array}$ & $\begin{array}{l}\text { Arsidas F, } \\
\text { Lísidas B' }\end{array}$ \\
\hline 2860 & $\begin{array}{l}\text { Flérida no acepta la acción de Lísidas. Combaten todos. } \\
\text { Huyen los hombres. }\end{array}$ & $\begin{array}{l}\text { Circe C, C', C', E', } \\
\text { Flérida C',-Lísidas } \\
\text { B', Arsidas H y F }\end{array}$ \\
\hline
\end{tabular}




\begin{tabular}{|l|l|l|}
\hline 2872 & $\begin{array}{l}\text { Lebrel le está enseñando habilidades a la mona (Clarín). } \\
\text { Coge un espejo, y al verse vuelve a su forma. }\end{array}$ & Lebrel S-Clarín T \\
\hline 2908 & $\begin{array}{l}\text { Antistes y otros llegan y descubren a Ulises, dormido. Le } \\
\text { dejan delante la armadura de Aquiles para que recuerde sus } \\
\text { deberes. }\end{array}$ & Antistes J-Ulises L \\
\hline 2944 & $\begin{array}{l}\text { Despierta Ulises. Renuncia a usar las armas de Aquiles. El } \\
\text { propio Aquiles muerto se le aparece y le exige que vaya a } \\
\text { su tumba a honrarle. Los griegos vienen a preguntar, y les } \\
\text { cuenta. Huirán sin ser vistos, como corresponde al riesgo } \\
\text { amoroso. Se van. }\end{array}$ & Ulises U y J-Circe E \\
\hline 3094 & $\begin{array}{l}\text { Llegan las damas con los hombres presos. Circe entiende } \\
\text { que Ulises se ha ido. Se despide desde el barco. Todos le } \\
\text { saludan, menos Circe, que lo llora. }\end{array}$ & \\
\hline 3194 & $\begin{array}{l}\text { Circe decide destruir el barco, generando llamas que brotan } \\
\text { del mar. }\end{array}$ & $\begin{array}{l}\text { Circe C y C',- } \\
\text { griegos A, A,,, }\end{array}$ \\
\hline 3214 & $\begin{array}{l}\text { Galatea ex machina declara que le va a hacer un camino de } \\
\text { agua tranquila a Ulises (en pago por la muerte de } \\
\text { Polifemo). }\end{array}$ & \\
\hline 3260 & Circe destruye su propio palacio, liberando a los animales. & \\
\hline
\end{tabular}

TABLA 1.-Formalización de las acciones, intenciones y conflictos en El mayor encanto, amor.

\section{MOTIVACIONES (PRETENSIONES) GENERADORAS DE CONFLICTOS}

A. Los griegos quieren salvarse (del mar).

A'. Salvarse (de la nueva geografía).

A'. (De las fieras).

A",. (De algo desconocido).

A'",'. (De Circe).

A ",,'. (De Brutamonte y los cíclopes).

B. Flérida y Lísidas se aman (al principio no se sabe, pero son árboles por eso).

B'. Lísidas quiere liberar a Flérida.

C. Circe quiere destruir a los hombres.

C'. (Quiere dominar y ser respetada, quiere representar una idea de sí misma, como despiadada).

C'. (Quiere castigar sus insultos).

D. Ulises quiere salvar a sus compañeros. (Juno le ayudará).

D' (Salvarlos de Brutamonte).

E. Circe quiere retener a Ulises.

E'. (Lo ama).

E'. (Lo desea).

F. Ulises quiere salvar a todos los prisioneros de Circe.

G. Lísidas y Flérida quieren (deben) ayudar a Ulises.

H. Arsidas quiere a Circe (contra la inclinación que nota que ella siente por Ulises).

I. Libia y Astrea quieren libertad para tener amantes (Lebrel y Clarín). 
J. Clarín y luego Antistes quieren volver a Grecia.

K. Lebrel y Clarín quieren el regalo de Circe.

L. Ulises ama a Circe. L'. (Finge que la ama).

M. Flérida teme a Circe. M'. (Finge que ama a Ulises).

N. Brutamonte quiere (o parece) vengar a Polifemo en todos los griegos.

O. Clarín quiere librarse de la dueña y el enano.

P. Lebrel quiere a Libia.

Q. Astrea quiere joyas.

R. Lebrel tiene miedo de Circe.

S. Quiere hacer negocio enseñando animales (como la mona que es Clarín).

T. Clarín quiere ser comprendido y volver a la forma humana.

U. Ulises tiene que cumplir lo impuesto por el sueño de Aquiles.

ESQUEMA 1.- Repertorio de motivaciones en El mayor encanto, amor. 


\begin{tabular}{|c|c|c|}
\hline \multicolumn{3}{|c|}{ La dama y galán Aquiles } \\
\hline Verso & Acciones & Motivaciones \\
\hline \multicolumn{3}{|c|}{ PRIMERA JORNADA } \\
\hline 1 & $\begin{array}{l}\text { Los marineros y Lidoro quieren sobrevivir a una } \\
\text { tempestad. }\end{array}$ & Marineros-A \\
\hline 9 & Lidoro se salva. Ve a Libio. & \\
\hline 29 & Buscan averiguar dónde están. & Lidoro B \\
\hline 42 & Alguien gime. & Lidoro B' \\
\hline 52 & $\begin{array}{l}\text { Se oyen músicas. Lidoro debe decantarse entre el llanto y } \\
\text { el canto. }\end{array}$ & Lidoro B'-B', \\
\hline 77 & Lidoro y Libio se esconden. & Lidoro y libio $\mathrm{C}$ \\
\hline 96 & $\begin{array}{l}\text { El rey, Ulises, Deidamia, dan a entender que van a hacer un } \\
\text { sacrificio a un templo, por Grecia contra Troya. }\end{array}$ & $\begin{array}{l}\text { Ulises, rey, } \\
\text { Deidamia D }\end{array}$ \\
\hline 117 & Lidoro decide seguirlos. & Lidoro B y B", \\
\hline 136 & $\begin{array}{l}\text { Se encuentran con Danteo, un servidor. Se aclara que } \\
\text { Lidoro es un príncipe prometido a Deidamia, que ahora se } \\
\text { encuentra sin sus posesiones por el naufragio. }\end{array}$ & Lidoro E \\
\hline 276 & $\begin{array}{l}\text { Danteo le explica que Ulises está aquí buscando la alianza } \\
\text { del rey, y para ello un oráculo favorable a la guerra. }\end{array}$ & Ulises F-Rey G \\
\hline 377 & $\begin{array}{l}\text { Lidoro entiende que está en la isla de Deidamia. Pero no } \\
\text { puede ir a presentarse por su mala situación actual. }\end{array}$ & Lidoro E-Lidoro C' \\
\hline 403 & $\begin{array}{l}\text { Se explica un vaticinio de Marte: Grecia ganará la guerra si } \\
\text { cuenta con Aquiles. Pero Venus oculta el modo de } \\
\text { identificar al héroe. }\end{array}$ & Marte H-Venus-I \\
\hline 449 & Lidoro intentará ocultar su identidad. & Lidoro C' \\
\hline 452 & $\begin{array}{l}\text { El rey condiciona su participación en la guerra a la } \\
\text { identificación de Aquiles. }\end{array}$ & Rey G' \\
\hline 468 & $\begin{array}{l}\text { Lidoro, de incógnito, delata la posición de Aquiles (por las } \\
\text { voces que oyó). Van grupos a buscarlo. }\end{array}$ & Lidoro E', Rey G' \\
\hline 507 & Lidoro se enamora de Deidamia. & Lidoro E”, \\
\hline 511 & $\begin{array}{l}\text { Deidamia lamenta el matrimonio que su padre ha } \\
\text { concertado con el desconocido Lidoro: rechaza casarse. }\end{array}$ & $\begin{array}{l}\text { Deidamia J-Rey y } \\
\text { Lidoro E }\end{array}$ \\
\hline 537 & $\begin{array}{l}\text { Deidamia teme que su prima Astrea, que debía llegar hoy } \\
\text { en barco, haya podido naufragar. }\end{array}$ & Deidamia K \\
\hline 564 & Música para Deidamia. & \\
\hline 582 & $\begin{array}{l}\text { Sale Aquiles encantado por la música, aunque se lo han } \\
\text { prohibido. }\end{array}$ & Aquiles L-Tetis M \\
\hline 638 & Aquiles se fascina por Deidamia, dormida. & Aquiles L' \\
\hline 684 & $\begin{array}{l}\text { Llega Sirene y alborota a Deidamia, que despierta. Aquiles } \\
\text { se enamora de Deidamia. }\end{array}$ & Aquiles L" \\
\hline 776 & Deidamia tiene miedo de Aquiles. & $\begin{array}{l}\text { Deidamia N-Aquiles } \\
\text { L', }\end{array}$ \\
\hline 790 & Sirene grita socorro. Aquiles se descubre ante Deidamia. & $\begin{array}{l}\text { Aquiles M- } \\
\text { Deidamia G' }\end{array}$ \\
\hline 804 & $\begin{array}{l}\text { Lidoro se enfrenta a Aquiles sin reconocerlo. Deidamia le } \\
\text { queda en deuda por su protección. }\end{array}$ & $\begin{array}{l}\text { Lidoro E'-Aquiles } \\
\text { L',: Deidamia O }\end{array}$ \\
\hline 818 & Ahora Lidoro ofrece su amistad a Aquiles. Aquiles, celoso, & Lidoro E' e G'- \\
\hline
\end{tabular}




\begin{tabular}{|c|c|c|}
\hline & la rechaza. & Aquiles L" \\
\hline 840 & $\begin{array}{l}\text { Deidamia quiere llevar a Aquiles ante los demás, pero a él } \\
\text { no le está permitido. }\end{array}$ & $\begin{array}{l}\text { Deidamia G'- } \\
\text { Aquiles M }\end{array}$ \\
\hline 855 & $\begin{array}{l}\text { Aquiles desaparece. Llegan los demás. Deidamia los } \\
\text { conduce hacia Aquiles. }\end{array}$ & Aquiles M-Todos G' \\
\hline 886 & $\begin{array}{l}\text { Libio se esconde, por miedo del monstruo Aquiles, que } \\
\text { precisamente se esconde junto a él. }\end{array}$ & Libio N-Aquiles M' \\
\hline 942 & $\begin{array}{l}\text { Aquiles pregunta a Libio por el amor y los celos, pero } \\
\text { Libio huye. }\end{array}$ & Libio N \\
\hline 975 & Todos rodean a Aquiles. & Todos G'-Aquiles M \\
\hline 1014 & $\begin{array}{l}\text { Tetis socorre a Aquiles. Aquiles lamenta la pérdida de } \\
\text { Deidamia. }\end{array}$ & Tetis M-Aquiles L" \\
\hline 1036 & Ulises jura encontrarlo. & s G' \\
\hline \multicolumn{3}{|c|}{ SEGUNDA JORNADA } \\
\hline 1040 & $\begin{array}{l}\text { Pelean Tetis y Aquiles: él quiere salir para conquistar a } \\
\text { Deidamia, ella trata de protegerlo. }\end{array}$ & Tetis M-Aquiles L" \\
\hline 1139 & $\begin{array}{l}\text { tis le explica su historia y le propone que se haga pasar } \\
\text { r Astrea, que ha muerto en el temporal. }\end{array}$ & $\begin{array}{l}\text { Tetis y Aquiles M y } \\
\text { L"-Deidamia K }\end{array}$ \\
\hline 1358 & as transforman a Aquiles en $\mathrm{A}$ & \\
\hline 1416 & $\begin{array}{l}\text { e las coplas cantadas: "monstruo en los } \\
\text { cielo. Se van. }\end{array}$ & Ulises F e G' \\
\hline 1486 & $\begin{array}{l}\text { rta que le avisa de que le van a mandar un } \\
\text { s a su nombre. }\end{array}$ & Lid \\
\hline 1500 & Vuelv & C'-E' $^{\prime}$ \\
\hline 1530 & llega. Lidoro intercambia su papel con Danteo, & $\begin{array}{l}\text { C'-E'- } \\
\text { nia J }\end{array}$ \\
\hline 1594 & $\begin{array}{l}\text { está en deuda con Lidoro por haberla protegido } \\
\text { s. }\end{array}$ & Deidamia O \\
\hline 1636 & ia no le preocupa el naufragio de Lidoro sino el & $\begin{array}{l}\text { De } \\
\text { y }\end{array}$ \\
\hline 1665 & $\begin{array}{l}\text { Quedan Lidoro, Danteo y Libio comentando cómicamente } \\
\text { la conversación. }\end{array}$ & \\
\hline 1690 & $\begin{array}{l}\text { Lidoro quiere escribir una petición a Deidamia que le dé } \\
\text { intriga sobre su identidad. }\end{array}$ & $\begin{array}{l}\text { Deidamia O-Lidoro } \\
\text { E", }\end{array}$ \\
\hline 1697 & $\begin{array}{l}\text { culo al rey. A una pregunta retórica, se } \\
\text { que Aquiles está "aquí". }\end{array}$ & Ulises G’ \\
\hline 1742 & $\begin{array}{l}\text { Se anuncia a Astrea (Aquiles). Se presenta a Deidamia con } \\
\text { ambigüedades. }\end{array}$ & $\begin{array}{l}\text { Deidamia K-Aquiles } \\
\text { L"-M", }\end{array}$ \\
\hline 1812 & $\begin{array}{l}\text { Aquiles oye al rey la promesa de sumarse a la guerra } \\
\text { cuando vaya también Aquiles, lo que lo alerta contra su } \\
\text { destino. }\end{array}$ & $\begin{array}{l}\text { Rey G e G'-Aquiles } \\
\text { M }\end{array}$ \\
\hline 1830 & $\begin{array}{l}\text { Al acaso, Danteo descubre "aquí" a Aquiles. Llega el barco } \\
\text { de Lidoro, atento a Deidamia, entristecida por la llegada de } \\
\text { su prometido. }\end{array}$ & $\begin{array}{l}\text { Lidoro C"y E"'- } \\
\text { Deidamia J }\end{array}$ \\
\hline 1867 & Tetis recuerda a Aquiles su peligro. & Tetis M-Aquiles L", \\
\hline 1882 & $\begin{array}{l}\text { Ulises decide tocar al arma para convocar los instintos de } \\
\text { Aquiles. }\end{array}$ & $\begin{array}{l}\text { Ulises G'-Aquiles M } \\
\text { y L', }\end{array}$ \\
\hline
\end{tabular}




\begin{tabular}{|c|c|c|}
\hline 1964 & $\mathrm{Al}$ acaso descubre Ulises que Aquiles está "con Deidamia". & $\begin{array}{l}\text { Ulises G'-Aquiles } \\
\text { M',' }\end{array}$ \\
\hline 1974 & Deidamia lamenta la llegada de Lidoro ante Aquiles. & Deidamia J \\
\hline 2047 & $\begin{array}{l}\text { Aquiles, a punto de descubrirse, habla de un tercero que la } \\
\text { ama, referido a sí mismo. }\end{array}$ & $\begin{array}{l}\text { Aquiles L"'-M y } \\
\text { Deidamia J y Lidoro } \\
\text { E" }\end{array}$ \\
\hline 2131 & $\begin{array}{l}\text { Llega Lidoro a tiempo de ser identificado por Deidamia } \\
\text { como su enamorado. Consecuentemente, resulta } \\
\text { descubierto y rechazado. }\end{array}$ & $\begin{array}{l}\text { Lidoro E" y C'- } \\
\text { Deidamia J }\end{array}$ \\
\hline 2182 & $\begin{array}{l}\text { Deidamia está enfadada con Aquiles por el malentendido. } \\
\text { Aquiles confiesa enigmáticamente su falsa identidad. }\end{array}$ & $\begin{array}{l}\text { Aquiles M'"'-L" y } \\
\text { Deidamia J y K e G' }\end{array}$ \\
\hline \multicolumn{3}{|c|}{ TERCERA JORNADA } \\
\hline 2224 & Aquiles de galán acude a una cita con Deidamia. & $\begin{array}{l}\text { Aquiles L", } \\
\text { Deidamia O }\end{array}$ \\
\hline 2351 & Deidamia debe casarse mañana con Lidoro. & $\begin{array}{l}\text { Aquiles L", L"'y } \\
\text { Deidamia O-Lidoro } \\
\text { E }\end{array}$ \\
\hline 2367 & Aquiles quiere atacar a los músicos enviados por Lidoro. & $\begin{array}{l}\text { Lidoro E-Aquiles } \\
\text { L", }\end{array}$ \\
\hline 2406 & $\begin{array}{l}\text { Llegan Lidoro y Libio. En la oscuridad Deidamia sale. Se } \\
\text { enfrentan Aquiles y Lidoro. }\end{array}$ & $\begin{array}{l}\text { Lidoro E",-Aquiles } \\
\text { L", y M", }\end{array}$ \\
\hline 2484 & $\begin{array}{l}\text { Ulises confunde a Lidoro con Aquiles y lo ataca ayudado } \\
\text { por Aquiles. }\end{array}$ & $\begin{array}{l}\text { Ulises G' y Aquiles } \\
\text { L"',-Lidoro E"," }\end{array}$ \\
\hline 2496 & $\begin{array}{l}\text { Aquiles huye. Lidoro y Ulises descubren que hay otro: } \\
\text { ¿quién? }\end{array}$ & $\begin{array}{l}\text { Ulises G', Lidoro } \\
\text { E,', }\end{array}$ \\
\hline 2624 & $\begin{array}{l}\text { Ulises explica el truco del estruendo militar y la tentación } \\
\text { militar de Aquiles. }\end{array}$ & $\begin{array}{l}\text { Ulises G y Lidoro } \\
\text { E",'-Aquiles M", y } \\
\text { P. }\end{array}$ \\
\hline 2700 & $\begin{array}{l}\text { Aquiles, de dama, presenta a Ulises. Deidamia duda de la } \\
\text { ingenuidad de Lidoro. }\end{array}$ & $\begin{array}{l}\text { Ulises G'-Aquiles } \\
\text { M','; Deidamia N', }\end{array}$ \\
\hline 2747 & $\begin{array}{l}\text { Ulises trae regalos de mujer y de hombre. Deidamia les } \\
\text { ofrece cosas a sus damas. }\end{array}$ & $\begin{array}{l}\text { Ulises G'-Aquiles } \\
\text { M",' }\end{array}$ \\
\hline 2820 & $\begin{array}{l}\text { También a Aquiles, que elige las armas (porque asume su } \\
\text { destino). }\end{array}$ & $\begin{array}{l}\text { Ulises G'y Aquiles } \\
\text { P-Aquiles M",' }\end{array}$ \\
\hline 2868 & Llegan el rey y Lidoro, que ven a Aquiles con las armas. & \\
\hline 2896 & $\begin{array}{l}\text { El rey informa del naufragio de Astrea, desenmascarando a } \\
\text { Aquiles. }\end{array}$ & $\begin{array}{l}\text { Todos K-Aquiles } \\
\text { M'”, }\end{array}$ \\
\hline 2924 & También propone que la boda sea mañana. & $\begin{array}{l}\text { Lidoro y rey E- } \\
\text { Aquiles L"' y } \\
\text { Deidamia O }\end{array}$ \\
\hline 2965 & $\begin{array}{l}\text { Aquiles parece conocer los ruidos militares, intenta } \\
\text { disimular, pero es el único hombre entre mujeres. }\end{array}$ & $\begin{array}{l}\text { Todos G' y Aquiles } \\
\text { P-Aquiles M',' }\end{array}$ \\
\hline 3004 & $\begin{array}{l}\text { Todos reaccionan (Lidoro, el rey, etc.). Aquiles desdeñado } \\
\text { por Deidamia acepta no descubrirse aún. }\end{array}$ & $\begin{array}{l}\text { Deidamia O y M"'- } \\
\text { Aquiles P }\end{array}$ \\
\hline 3066 & $\begin{array}{l}\text { Ulises lo encuentra, y Aquiles cae en una trampa verbal. } \\
\text { Acepta ir a la guerra. }\end{array}$ & $\begin{array}{l}\text { Ulises G' y Aquiles } \\
\text { P-Aquiles M',' y } \\
\text { M',' }\end{array}$ \\
\hline
\end{tabular}




\begin{tabular}{|l|l|l|}
\hline 3206 & Aquiles explica a Deidamia por qué se va. & $\begin{array}{l}\text { Aquiles P y Ulises } \\
\text { G'-Deidamia O }\end{array}$ \\
\hline 3244 & $\begin{array}{l}\text { Deidamia pide que Aquiles se quede. Pero la música militar } \\
\text { lo atrae. }\end{array}$ & $\begin{array}{l}\text { Deidamia O-Aquiles } \\
\text { P }\end{array}$ \\
\hline 3297 & $\begin{array}{l}\text { Llega Lidoro y riñen. } \\
\text { Aquiles L', y L'"'- } \\
\text { Lidoro E' y E', }\end{array}$ \\
\hline 3311 & Deidamia llama a la gente. & $\begin{array}{l}\text { Rey Q-Aquiles L' y } \\
\text { Deidamia O }\end{array}$ \\
\hline 3320 & Aquiles se descubre públicamente. & Rey Q-Ulises F' \\
\hline 3327 & $\begin{array}{l}\text { El rey quiere matarlo por el honor de Deidamia, pero } \\
\text { Ulises pasa a defenderle. }\end{array}$ & Tetis M y Ulises F' \\
\hline 3336 & Tetis explica la importancia Aquiles para los griegos. \\
\hline 3351 & $\begin{array}{l}\text { Se le concede el matrimonio con Deidamia, y todos lo } \\
\text { aceptan, incluido Lidoro. }\end{array}$ & \\
\hline
\end{tabular}

TABLA 2.-Formalización de las acciones, intenciones y conflictos en La dama y galán Aquiles.

\section{MOTIVACIONES GENERADORAS DE CONFLICTOS}

A. Lidoro y los marineros quieren salvarse de la tempestad.

B. Quiere saber dónde está.

B'. Quiere saber quién gime.

B'. Quiere saber quién canta.

C. Lidoro quiere que no los encuentren.

C'. Lidoro quiere encubrir su estado pobre.

C'. Lidoro quiere que le lleguen pronto sus riquezas.

D. Hacer un sacrificio para saber el futuro de la guerra de Troya.

E. Lidoro quiere casarse con Deidamia.

E'. Lidoro quiere ganar méritos ante el rey.

E'. Lidoro está enamorado de Deidamia.

E'". Lidoro guarda su honor.

F. Ulises quiere contar con la alianza del rey

F'. Ulises quiere ganar la guerra de Troya.

G. El rey solo quiere ayudar a Ulises con garantías.

G'. El rey quiere encontrar a Aquiles.

H. Marte quiere ayudar a los griegos.

I. Venus quiere ayudar a los troyanos.

J. Deidamia quiere ser soltera.

K. Deidamia quiere ver a su prima Astrea.

L. Aquiles se fascina por la música.

L'. Aquiles se fascina por las mujeres.

L'. Aquiles se enamora de Deidamia.

L"'. Aquiles tiene celos de Lidoro.

M. Tetis le ha prohibido a Aquiles que se dé a conocer. 
M'. Aquiles busca la cueva para esconderse.

M'. Tetis protege a Aquiles.

M'". Aquiles oculta su verdadera identidad.

M','. Aquiles se compromete con Deidamia a ocultarla.

N. Deidamia tiene miedo de Aquiles. Libio tiene miedo de Aquiles.

N'. Deidamia tiene miedo de Lidoro (y de sus celos).

O. Deidamia está en deuda con Lidoro por su protección.

O’. Deidamia está enamorada de Aquiles.

P. Aquiles tiene la naturaleza del guerrero.

Q. El rey quiere guardar su honor.

ESQUEMA 2.- Repertorio de motivaciones en La dama y galán Aquiles.

Formalizadas las pretensiones de los personajes a lo largo de cada comedia, podemos observar la alternancia de varios conflictos de distinta extensión que se van entrelazando hasta la resolución final. Pero esto se comprende mejor en los diagramas que presentamos a continuación (Figuras 1 y 2): en el eje vertical se recogen las motivaciones en el mismo orden que en los esquemas 1 y 2 , pero en orden inverso, a partir de la horizontal inferior, de manera que den la sensación de superponerse a medida que se desarrolla el entramado de conflictos (aunque sacrificamos la convención de lectura que empieza por arriba). La motivación que señalemos con la $\mathrm{A}$ estará en la fila más baja del gráfico.

Por su parte, el eje horizontal irá ordenado de acuerdo con los números de los versos. Las columnas correspondientes a los versos en los que se alude a una motivación irán rellenadas en las cuadrículas de las líneas correspondientes a esa motivación. El aspecto será por lo tanto el de líneas horizontales sombreadas a distintas alturas, que corresponderán a las motivaciones que se desarrollan a lo largo de esos versos.

Por supuesto, pueden aparecer varias motivaciones simultáneamente, sea porque están en conflicto o porque coexisten pacíficamente. Si la motivación que se hace presente en un pasaje no entra en conflicto con otra, el color utilizado será el gris claro; si el caso es que sí entra en conflicto con otra, el gris oscuro; si el conflicto se hace explícito y deviene enfrentamiento, su color será el negro.

A lo largo de estas comedias, algunos conflictos quedan abiertos a partir de sus primeras expresiones y se van cerrando paulatinamente o se transforman sutilmente en otros, de modo que se mantiene en la memoria de los espectadores su presencia virtual y participan en la acumulación de tensiones y en la preparación del desenlace. Pero resulta difícil delimitarlos para definir esa textura dramática, de manera que no trataremos de reflejar en nuestros grá- 
ficos la presencia latente de motivaciones que no son declaradas ni sugeridas directamente por los personajes, limitándonos a apuntar las que sí lo son.

El mayor encanto, amor (Tablas 1 y 2; Figura 1) tiene 3.303 versos $^{1}$, un tamaño perfectamente adecuado a las convenciones de su género, y está dividido, como las otras dos comedias estudiadas y la mayoría de las de su tiempo, en tres jornadas de una duración más o menos similar. Hemos encontrado en ella 34 motivaciones, algunas relacionadas genéticamente entre sí, formando 21 grupos. Por ejemplo, la primera (A) corresponde al deseo de los marinos griegos de escapar a la tormenta que agita su barco en el mar, que deriva pronto en la motivación de escapar a una geografía desconocida o adversa (A'), y a su vez pronto cede el paso a la de salir inmune a los probables ataques de unas extrañas fieras que los rodean (A').

Las motivaciones tienen desarrollos verbales variables, que van desde un único verso hasta los 338 que se emplean en dar a entender que Circe desea destruir o dominar a todos los hombres, eje de la obra que aparece muy desarrollado al inicio.

Por su parte, en La dama y galán Aquiles (Tablas 1 y 2; Figura 2) podemos contar 3.364 versos, y se repite una división en tres jornadas, aproximadamente equivalentes en extensión. Encontramos 35 motivaciones repartidas en 18 grupos. Por su parte, la extensión máxima concedida a las explicaciones relacionadas con una motivación de forma continuada corresponde al conflicto interno entre las motivaciones L" (Aquiles se ha enamorado de Deidamia) y M (Aquiles no puede violar la prohibición de su madre Tetis de darse a conocer), que tiene lugar al principio de la Jornada II, continuando además con lo dejado en suspenso al final de la primera, y que ocupa 318 versos. Encontramos otra que ocupa una extensión aun mayor, 331 versos, pero aparece entreverada con otras motivaciones, y corresponde a la tensión entre el carácter guerrero de Aquiles, que el héroe se esfuerza por reprimir (P) y su compromiso de ocultar su identidad (M',') al final de la comedia.

\footnotetext{
${ }^{1}$ En la corrección manuscrita del final, la alternativa de Calderón cuenta seis versos menos (Calderón, 2013a: 83).
} 


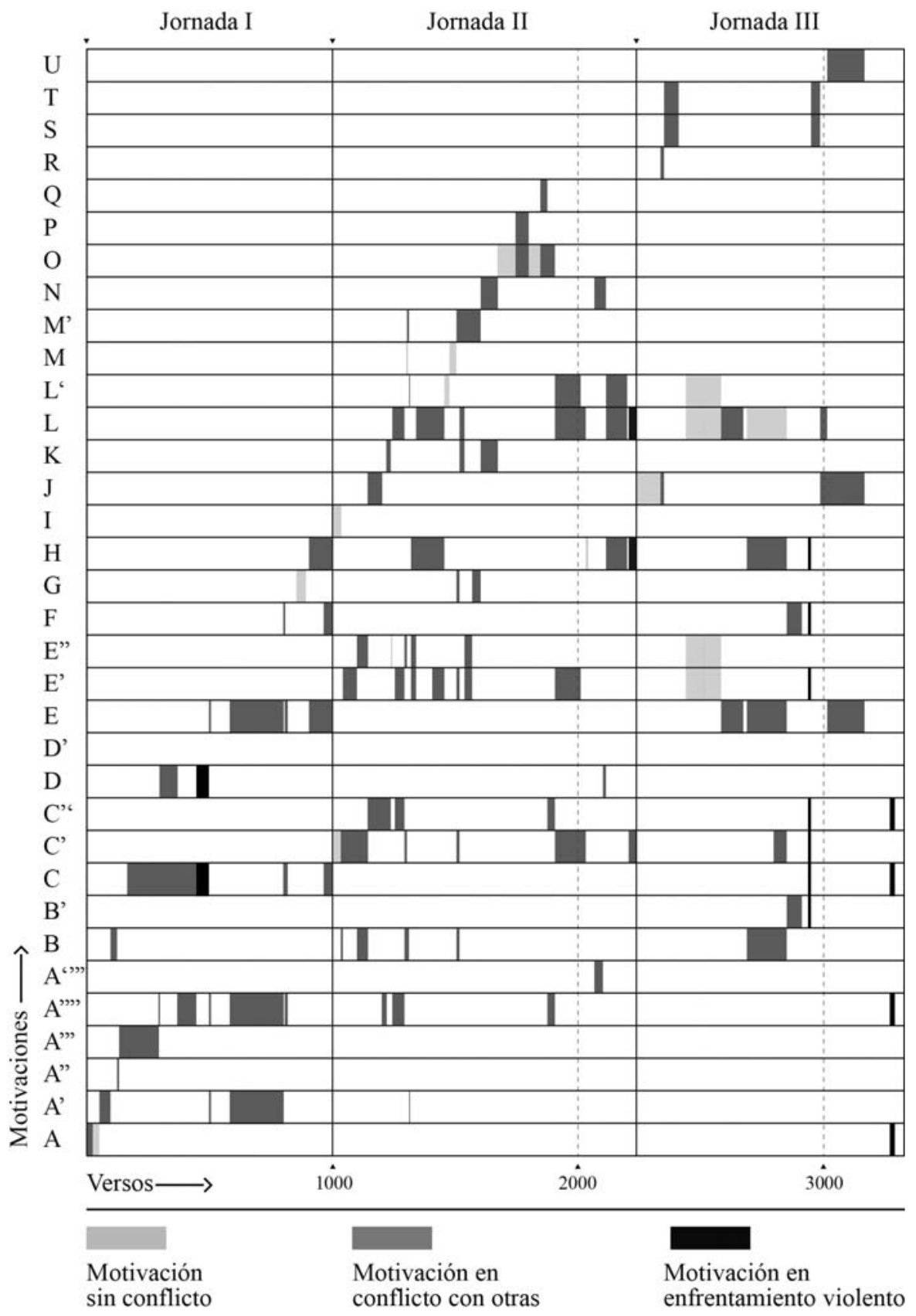

FIGURA 1.-Gráfico de distribución de motivaciones en El mayor encanto, amor. 


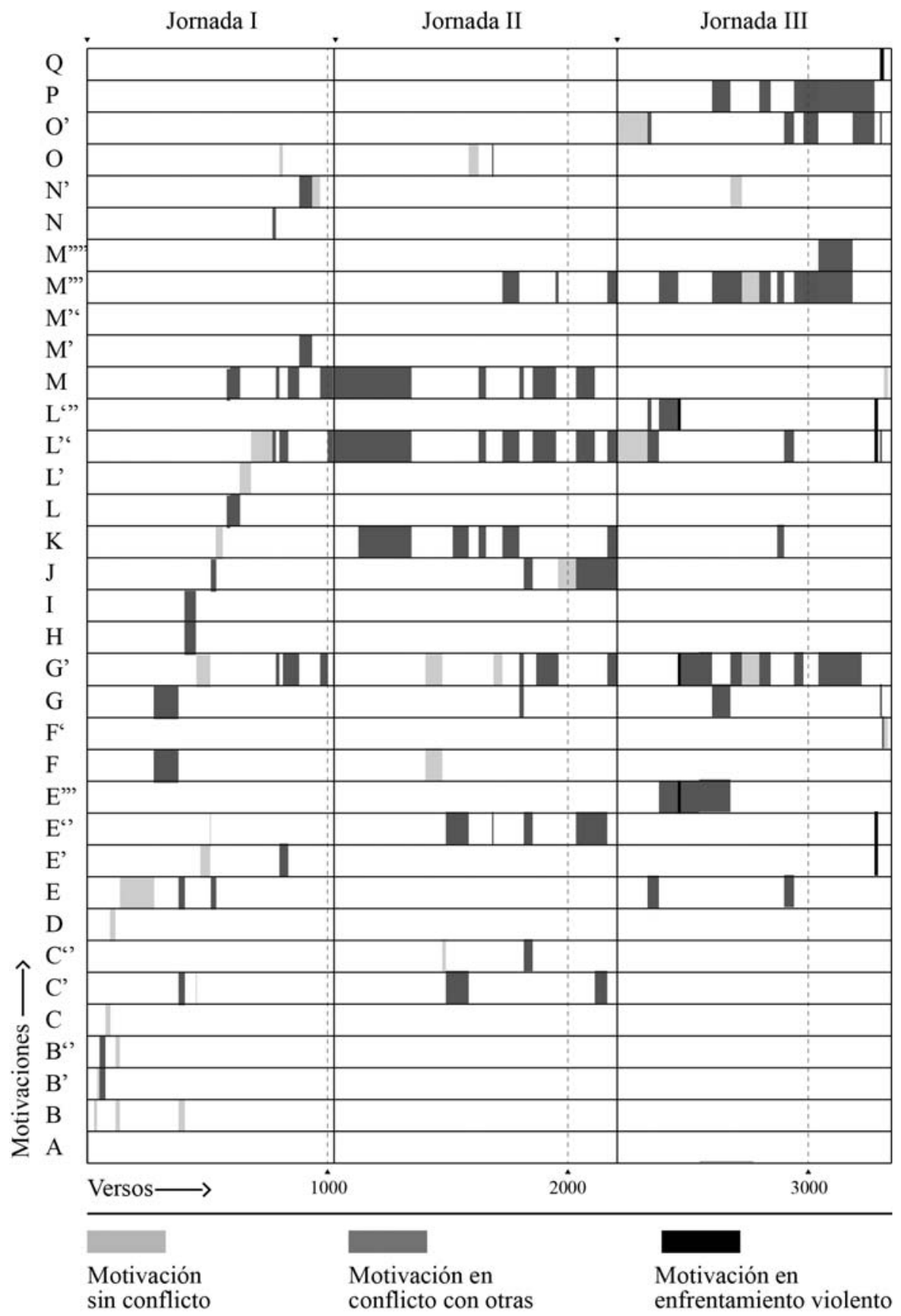

FIGURA 2.-Gráfico de distribución de motivaciones en La dama y galán Aquiles. 


\section{COMPARACIÓN}

Aparte de las ventajas descriptivas de transcribir el esquema de tensiones, el interés principal está en utilizarlo para comparar las comedias y resaltar los rasgos en común y las diferencias que encontremos en su representación gráfica. Pero antes señalaremos algunos aspectos que son evidentes desde la lectura misma de las obras.

Ambas comedias presentan características muy parecidas, lo que en principio está en consonancia con lo esperable en la comedia áurea (con excepciones debidas a particularidades de la ocasión, a la importancia relativa de la música o del aparato escénico, etc.). Tienen una longitud similar, poco superior a los 3000 versos, y un número y disposición de los conflictos bastante parecido: las dos se ordenan en torno a un conflicto central que se ramifica en otros de menor importancia o se adorna con ellos.

Nuestro autor muestra por otro lado una clara pretensión de no aburrir, evitando desarrollar durante demasiado tiempo y sin interrupción un mismo conflicto (como ya hemos visto, los casos excepcionalmente largos ocupaban 338 y 331 versos, siempre en relación con conflictos centrales de cada comedia y siempre implicando simultáneamente a otras motivaciones paralelas). Prefiere alternar varias tensiones y desarrollarlas paulatinamente, a ser posible enlazándolas por medio de personajes, temas, etc. En esto se opone diametralmente a la manera de otros autores que sí se permiten extenderse en una situación que les resulta poéticamente fértil (Shakespeare o Chéjov, por ejemplo).

Aparte de estos rasgos generales, nuestra formalización permite observar algunas preferencias dramáticas comunes a las dos comedias:

1. La representación gráfica evidencia un esfuerzo por llevar a cabo un despliegue enorme de motivaciones enfrentadas desde distintos ángulos y perspectivas (34 y 35, como hemos señalado), que van cambiando de escena en escena pero que quedan siempre cerradas a medida que se acerca el final (en claro contraste con los perseguidores de la verosimilitud a ultranza). Estas motivaciones se agrupan en un número menor de conflictos más complejos y ramificados.

En algunos casos, unas pocas situaciones reales dan lugar a múltiples situaciones en el plano de lo conjetural o ficticio (y el engaño es uno de los temas favoritos de la estética barroca); en otros, de hecho hay varias líneas argumentales. Uno de los mejores ejemplos de lo primero podemos encontrarlo, fuera del corpus, en Casa con dos puertas mala es de guardar, que propone una situación germinal extremadamente simple que se complica por la multiplicación de las interpretaciones equivocadas con que los pocos personajes especulan. Sin llegar a ese extremo, algunas ficciones metateatrales tienen también lugar en los fingimientos lúdicos o interesados de Ulises y Flérida y 
de Ulises y Circe en El mayor encanto, amor, o en la suplantación de Astrea por Aquiles en La dama y galán Aquiles. En los otros casos, las tramas que se entrecruzan son más o menos reales.

2. Al principio de las dos obras un conflicto conductor (figura convencional reconocible en gran parte del teatro calderoniano) se extiende a medida que se van presentando las verdaderas motivaciones de los personajes y los conflictos centrales. En ambos casos se trata de una tormenta, aunque en otras obras de Calderón encontramos situaciones convencionales diversas: batallas, despeñamientos, irrupciones de fieras, etc.

3. En los finales de las jornadas primera y segunda varios personajes expresan simultáneamente sus conflictos en un momento climático pero provisionalmente irresoluble, como un acorde general que deja la obra en suspenso. De manera coherente, los principios de las jornadas segunda y tercera tienden a ofrecer explicaciones que resumen o aclaran lo más importante de lo ocurrido en el final anterior.

4. La máxima confusión se encuentra hacia el final de la jornada segunda, mientras que en la tercera los personajes, que ya han declarado sus intenciones, se enfrentan de manera más directa, declarando la guerra o decidiéndose en todo caso a resolver sus conflictos sin ocultar sus intenciones a los que ya son claramente sus enemigos.

5. Otro objetivo bien cuidado es el de evitar que encontremos en cualquier punto un impás en el que todos los conflictos estén cerrados, si no es el final. Este precepto lopesco de satisfacer las expectativas del público solo al final del espectáculo originaba una burla del propio Calderón en uno de los pocos casos en que consentía que ocurriese lo contrario, en Mañanas de abril y mayo: al final de la segunda jornada parece que todos los conflictos están resueltos antes de tiempo, y el gracioso da por acabada la obra con un discurso metateatral, cuando viene a suceder un nuevo desequilibrio que abre la necesidad de la tercera jornada. Por su parte, en las dos comedias descritas el entramado es perfectamente coherente y se entreteje sin cesuras hasta la escena final.

6. Además, las interrupciones de la acción son pocas y en todo caso breves, muy espaciadas en el desarrollo de la trama, de manera que nunca encontramos una sucesión de escenas cómicas que supere los 50 versos, a no ser que adquiera entidad de trama paralela y se continúe en escenas posteriores: es lo que ocurre con Lebrel en El mayor encanto, cuando se ve envuelto en una sucesión de desgracias cómicas por haber faltado al respeto a Circe. Tampoco encontramos en ningún caso una sucesión de una escena cómica y otra musical, sino que más bien aparecen de manera aislada, con la evidente intención de no interrumpir la progresión de la trama durante demasiado tiempo.

7. Respecto a la persistencia de las motivaciones, hay que señalar que la distribución por el conjunto del gráfico es bastante homogénea, una vez que 
han ido expresándose, naturalmente, una por una. El dibujo que vemos en los dos gráficos empieza en diagonal, consecuencia evidente del planteamiento elegido: las hemos situado así por orden de aparición. Pero una vez presentes en la memoria del público, ninguna de las intenciones de los personajes es abandonada gratuitamente si no es que se transforma en otra intención variante de la primera o bien es resuelta. De todas formas, pocos conflictos vienen resueltos antes de mediada la tercera jornada: la excepción pueden ser los conflictos iniciales, diseñados exclusivamente para poner en marcha el drama, y que pueden ser dejados de lado en el mismo momento en que las intenciones específicas de cada personaje son descubiertas. Así, la tormenta que amenaza las vidas de los marinos griegos en El mayor encanto puede calmarse una vez que ellos se encuentran en una tierra claramente peligrosa; la otra tormenta, que pone en peligro la vida de Lidoro y sus marineros en La dama, es innecesaria cuando este descubre que alguien clama escondido y que se aproxima una procesión ritual con música.

No encontramos, en cambio, una clara preferencia por disponer todos los conflictos nuevos en la primera jornada, ni por desarrollarlos en la segunda y concluirlos en la tercera (más bien solo al final de la tercera). Aunque la mayoría de los conflictos están presentes en la primera jornada de La dama, todavía aparece uno importante en la segunda, y en El mayor encanto siguen apareciendo nuevos conflictos durante las jornadas segunda y tercera. De esta manera, el esquema podría acercarse más a la idea de desarrollo continuo que la tradicional de planteamiento, nudo y desenlace.

\section{CONCLUSIONES}

Más allá de las dificultades derivadas del indudable componente subjetivo que hay en la selección de las motivaciones según su expresión en las obras, podemos aceptar que la realización de los gráficos ha permitido probar que, mediante ciertos instrumentos bien definidos, es posible formalizar el repertorio de intenciones atribuidas a los personajes para atender a su disposición en el tiempo más homogéneo y objetivo de la recepción (sea representación, lectura, etc.), marcando un particular diseño del ritmo narrativo o dramático. Este entramado de tensiones se despliega en los textos con extensión temporal según esquemas variopintos, más o menos cuidados, y merece una atención especial. 


\section{BIBLIOGRAFÍA}

Antonucci, F. (2010): "La segmentación métrica, estado actual de la cuestión”, Teatro de Palabras, 4, pp. 77-97.

Arellano, Ignacio (2001): Estructuras dramáticas y alegóricas en los autos de Calderón, Kassel/ Pamplona, Edition Reichenberger/Universidad de Navarra.

Arellano, Ignacio (2006): El escenario cósmico. Estudios sobre la Comedia de Calderón, Pamplona/Madrid/Frankfurt, Universidad de Navarra/ Iberoamericana/Vervuert.

Calderón de la Barca, Pedro (2013a): El mayor encanto, amor, Alejandra Ulla Lorenzo (ed.), Madrid/Frankfurt, Universidad de Navarra/Iberoamericana/Vervuert.

Calderón de la Barca, Pedro (2013b): La dama y galán Aquiles (El monstruo de los jardines), Tatiana Alvarado Teodorika (ed.), Madrid/Frankfurt, Universidad de Navarra/Iberoamericana/ Vervuert.

Cook, Nicholas (2004): "Forme et syntaxe", en Jean-Jacques Nattiez (dir.), Musiques. Une encyclopédie pour le XXI siècle, Arles, Actes Sud/Cité de la Musique, vol. II, pp. 162-188.

Couderc, Cristoph (2006): Galanes y damas en la comedia nueva, Madrid/Frankfurt, Iberoamericana/Vervuert.

Courtés, Joseph (1997): Análisis semiótico del discurso. Del enunciado a la enunciación, Madrid, Gredos.

Déodat-Kessedjian, Marie-Françoise (2002): “Algunas pautas para el estudio del tiempo en el teatro de Calderón”, en Ignacio Arellano (ed.), Calderón 2000. Homenaje a Kurt Reichenberger en su 80 cumpleaños, Kassel, Edition Reichenberger, vol. I, pp. 385-398.

Fischer-Lichte, Erika (1999): Semiótica del teatro, Madrid, Arco/Libros.

Genette, Gèrard (1989): Figuras III, Barcelona, Lumen.

Oleza, Joan (2009): “Trazas, funciones, motivos y casos. Elementos para el análisis del teatro barroco español", en Alberto Blecua, Ignacio Arellano y Guillermo Serés (eds.), El teatro del siglo de oro. Edición e interpretación, Pamplona/Madrid/Frankfurt, Universidad de Navarra/ Iberoamericana/Vervuert, pp. 321-348.

Serralta, Frédéric (1987): Antonio de Solís et la "Comedia" d'intrigue, Toulouse, France-Ibérie recherche/Université de Toulouse-Le Mirail.

Ubersfeld, Anne (1989): Semiótica teatral, Madrid, Cátedra.

Weber de Kurlat, Frida (1975): "Introducción biográfica y crítica", en Lope de Vega, Servir a señor discreto, Madrid, Castalia, pp. 9-51.

Weber de Kurlat, Frida (1976): "Hacia una morfología de la Comedia del Siglo de Oro (con especial atención a la «comedia urbana»)", Anuario de letras, 14, pp. 101-138.

Fecha de recepción: 31 de marzo de 2015

Fecha de aceptación: 8 de febrero de 2016 